\title{
Improving the management of mealybugs (Pseudococcidae) in apple orchards
}

\author{
P.L. Lo ${ }^{1}$, J.T.S. Walker ${ }^{1}$, T.M. Fraser² and D.W. Manktelow ${ }^{3}$ \\ ${ }^{1}$ The New Zealand Institute for Plant \& Food Research Limited, Private Bag 1401, \\ Havelock North, Hastings 4157, New Zealand \\ ${ }^{2}$ Fruition Horticulture, PO Box 966, Hastings, New Zealand \\ ${ }^{3}$ Manktelow E Associates, PO Box 3415, Hawke's Bay Mail Centre, Napier 4142, New \\ Zealand \\ Corresponding author: Peter.Lo@plantandfood.co.nz
}

\begin{abstract}
Mealybug infestations in New Zealand apples declined when integrated fruit production was implemented in the late 1990s. In Hawke's Bay, however, mealybugs have recently become an increasing problem. The mean incidence of mealybugs at harvest increased from $1.7 \%$ in 2008 to $2.2 \%$ in 2010. In 2009 and 2010, almost 50\% of blocks had a higher incidence than the previous year. Analysis of spray diaries suggested that spray programmes up to 2009-10 were inadequate to maintain long-term suppression of mealybugs. Key factors were the number of insecticide sprays, their time of application, and the choice of product, but not spray coverage. Consequently, in spring 2010, orchard managers were encouraged to follow a 'best practice' spray programme against mealybugs, which led to markedly improved mealybug control. At harvest in 2011, the mean incidence was $0.7 \%$ and just $14 \%$ of blocks had more mealybugs than the previous year while almost $60 \%$ had fewer.
\end{abstract}

Keywords Pseudococcus, mealybug, infestation, buprofezin.

\section{INTRODUCTION}

Mealybugs can infest the calyx and stem end of apples, and consequently pose cosmetic and quarantine problems for the export pipfruit industry. The species involved are Pseudococcus calceolariae (citrophilus mealybug), P. longispinus (longtailed mealybug) and P. viburni (obscure mealybug) (Charles 1993). Mealybugs were a significant pest of pipfruit throughout the 1990s when control was based on intensive use of broad spectrum pesticides that led to the development of resistance to organophosphate insecticides in some populations (Charles et al. 1993).
Following the introduction of integrated fruit production (IFP) in the mid 1990s and the introduction of selective insecticides (Walker et al. 1997), mealybugs became a relatively minor pest issue. In recent years, however, they have become an increasing problem. In Hawke's Bay, the incidence of mealybugs in apple crops has been rising.

The permissible degree of insect infestation of export apple crops is a complex topic. This depends on the market destination of the fruit and whether the pest found is actionable in that 
country (i.e. not permitted) or non-actionable. If non-actionable, then the Ministry of Agriculture \& Fisheries export certification programme allows an aggregate of all such pests up to $2 \%$ fruit infestation.

The objectives of this paper were to: (1) quantify the incidence of mealybugs in fruit at harvest in Hawke's Bay apple orchards, (2) identify key factors responsible for the rising incidence of mealybugs and (3) improve guidelines for better mealybug control.

\section{METHODS}

The incidence of mealybugs at harvest from 2008 to 2011 was assessed from bins of fruit on orchards managed by one packhouse supply group in Hawke's Bay. On each orchard block, a sample of 100 fruit from each of 10 randomly chosen bins (total of 1000 fruit/block) was inspected for pests. Apples were classified as being infested if a mealybug was seen or if there was sooty mould in the calyx indicating the presence of a mealybug. The number of blocks sampled varied from 74 to 112 per year and are given in the Results section.

Spray diaries from the orchards where fruit was inspected during the 2007-08 to 2010-11 seasons were collated and analysed with regard to insecticide applications targeting mealybugs. Factors covered included insecticide choice, number of applications, spray timing, product and water rates per hectare. In spring 2010, orchard managers from the supply group were supplied with 'best practice' guidelines for the control of mealybugs written by Plant \& Food Research, and encouraged to adopt these recommendations.

Twenty-four blocks that had a high incidence of mealybugs in 2009-10 were also visited at the start of the following season to check on the performance of their sprayers. The sprayers used on these blocks were recalibrated and the managers were supplied with 20 pieces of water-sensitive paper and instructions on where to place them in trees. Papers were to be placed in areas where mealybugs typically overwinter, e.g. trunks, large branches, burr knots. These trees were sprayed during the dormant period with the sprayer in its usual configuration and operating conditions. Spray coverage on the papers was analysed and where necessary, growers were advised how to modify their sprayer set-ups before the application of any mealybug insecticide in early spring 2010 .

Percentage data were arcsine transformed before analysis. A one-way ANOVA was performed to compare mealybug infestations in the 4 years. Groups of orchards where there were data for 2 successive years were analysed by a paired sample $t$-test.

\section{RESULTS}

\section{Mealybug infestations}

Infestations of mealybugs varied significantly during the study $(\mathrm{P}<0.001)$. The mean $( \pm$ SEM $)$ incidence of mealybug-infested fruit at harvest was $1.7 \%( \pm 0.25)$ in $2008(\mathrm{n}=74), 1.6 \%( \pm 0.22)$ in $2009(\mathrm{n}=101), 2.2 \%( \pm 0.30)$ in $2010(\mathrm{n}=112)$ and $0.7 \%( \pm 0.10)$ in $2011(\mathrm{n}=112)$. Data for 2 successive years for the same blocks are shown in Figure 1. The incidence of mealybugs in 2009 was similar to that in 2008, whereas it increased significantly between 2009 and 2010. This trend was reversed in 2011, when there was a $61 \%$ decrease in mealybug infestation compared with 2010.

When the same blocks were compared in 2 successive years, in both 2009 and 2010, the percentage of fruit infested by mealybugs had increased by at least $0.3 \%$ on almost half the blocks surveyed, whereas in 2011 only 14\% of blocks had more mealybugs than the previous year. Conversely in 2009 and 2010, infestations were at least $0.3 \%$ lower on $30-37 \%$ of blocks, compared with $58 \%$ in 2011.

The percentage of fruit infested by mealybugs per block is categorised in Figure 2. The proportions in each category were similar in the years $2008-2010$ so these data were averaged. The key differences between infestations from 200810 and 2011 were a higher proportion of blocks with $\leq 0.5 \%$ of fruit infested in 2011 (65\%) than in 2008-10 (39\%) and fewer severely infested blocks (i.e. those with $>2 \%$ mealybug, $7 \%$ compared with 27\%). 


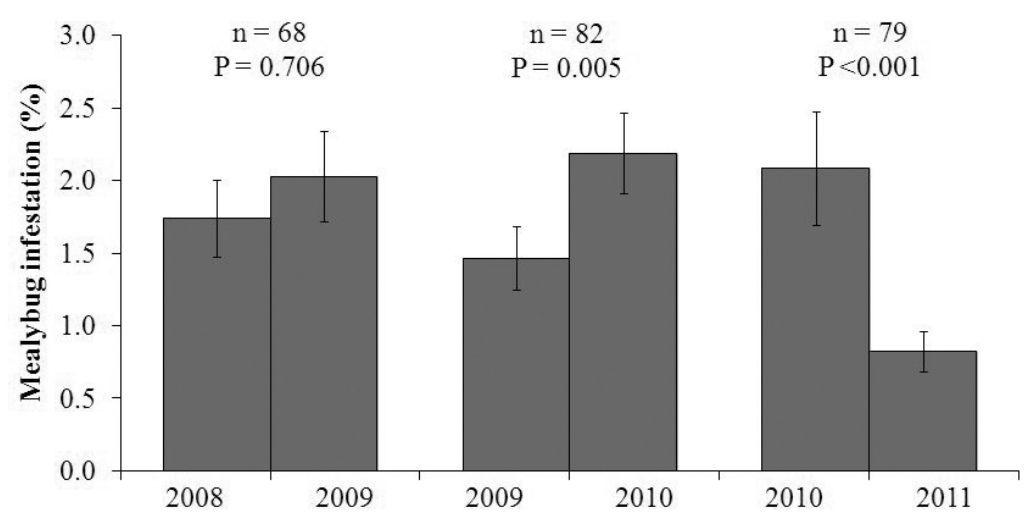

Figure 1 Mean $( \pm$ SEM) incidence of mealybug infestation (presence of mealybugs or calyx sooty mould) on Hawke's Bay apples at harvest comparing the same blocks in 2 successive years. The numbers of blocks compared are shown above the columns with the ANOVA test results.

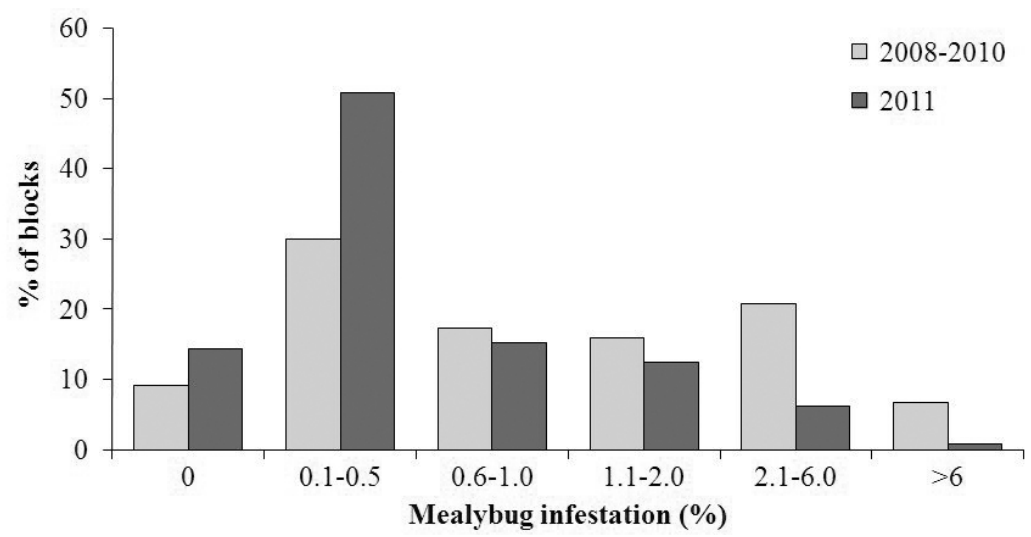

Figure 2 Percentage of Hawke's Bay apple blocks having different categories of mealybug infestation on fruit at harvest for 2008-2010 combined compared with 2011.

\section{Spray programmes}

Buprofezin $\left(\right.$ Applaud $^{\circledR}$, Mortar $^{\mathrm{TM}}$ ) was the principal insecticide used against mealybugs. Thiacloprid $\left(\right.$ Calypso ${ }^{\circledR}$ ) was targeted mainly towards scale insects but it also has activity against mealybugs. In 2008, growers applied ca 1 buprofezin spray per block and there was very limited use of thiacloprid (Figure 3). The following year, less buprofezin was used but $80 \%$ of blocks received at least one thiacloprid spray. By 2010, the use of buprofezin had declined to 0.5 applications per block, while thiacloprid use remained unchanged at ca 1 per block. In contrast, for the 2010-11 season most growers used 2 buprofezin sprays and no thiacloprid. In 2010-11, the buprofezin sprays were applied around late August (the 'green tip' tree growth stage) and late September (preflowering 'pink' stage). In previous years only the earlier spray was applied.

Product and water rates for buprofezin and thiacloprid sprays were available only for the 200910 season. All buprofezin sprays were applied at 2000 litres/ha and at the correct active ingredient rate, except one where both of these rates were halved. In contrast, water rates for thiacloprid varied between 500 and 1000 litres/ha. Although $69 \%$ of these sprays were at the recommended active ingredient rate of $288 \mathrm{ml}$ per hectare, $31 \%$ 


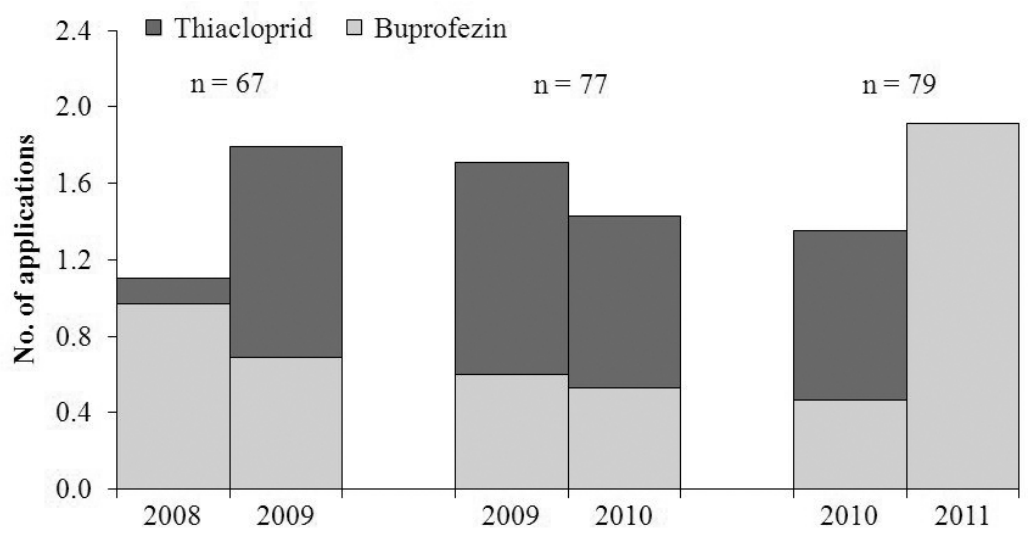

Figure 3 Mean number of insecticide applications against mealybugs on Hawke's Bay apples comparing the same blocks in two successive years. The numbers of blocks compared are shown above the columns.

used less than the label rate, and typically only $96-$ $144 \mathrm{ml} / \mathrm{ha}$.

\section{Sprayer performance}

The great majority of sprayers $(22 / 24)$ was judged to have achieved excellent coverage. On these machines, $>80 \%$ of the water-sensitive papers had been thoroughly wetted. In two cases, however, there were gaps in the spray coverage. One sprayer failed to adequately wet the lower trunk of the tree, while the other machine had poor coverage in the top third of the tree. The respective nozzle configurations of these sprayers were modified as necessary.

\section{DISCUSSION}

There has been a slow increase in mealybug incidence in Hawke's Bay apple crops over several years, to the point where mealybugs alone infested more than $2 \%$ of fruit in many apple crops. The main factor responsible for this situation appeared to be an inadequate insecticide programme. For 2 years before the 2010-11 season, growers had been typically applying $\sim 0.5$ buprofezin and $\sim 1$ thiacloprid spray per block per year. Compared with what is regarded as an optimum programme for mealybug control, growers were relying on (a) too few applications of buprofezin and a less than optimum time of application, and (b) a less effective insecticide against mealybugs (thiacloprid), which was often applied below the label rate. Too few growers were using buprofezin and it was being applied too early in the season.

In September 2010, growers were advised to make two applications of buprofezin and include a later time of application. Following these recommendations, mealybug control was greatly improved and the trend of rising mealybug incidence was reversed in 2011. There was a dramatic reduction in the severity of infestations across a large group of orchards. Because both the number and timing of buprofezin sprays changed it is not certain which was the more crucial factor. The later timing of the second spray was likely to be important, because buprofezin is effective against juvenile mealybugs, which are more abundant in early spring than in late winter. However, no growers applied just one buprofezin at the later timing.

The improved mealybug control in 2011 also coincided with growers using buprofezin instead of thiacloprid. A large proportion of thiacloprid applications had been applied at active ingredient rates less than that recommended on the label. Although this was likely to have compromised its efficacy, there was no correlation between the rate of thiacloprid used and the degree of mealybug control. Any relationship, however, may have been confounded by other factors, such as the use of buprofezin. 
Three factors that are believed to have played little or no part in the initial poor mealybug control and subsequent reduction in mealybug infestation were the buprofezin application volume, active ingredient rate and sprayer performance. Water rates for buprofezin applications were 2000 litres/ha in both 2010 and 2011, so were not a factor in the improved control. Similarly the sprayer calibrations and water-sensitive paper tests indicated that the great majority of the machines were set up appropriately to deliver good spray coverage, so poor equipment performance can also be discounted. In all cases the correct active ingredient rate for buprofezin was used by growers.

\section{CONCLUSIONS}

Several factors that appear to have contributed towards the less than adequate control of mealybugs in Hawke's Bay were identified, while other possible causes were eliminated. Pipfruit growers had mealybugs under good control with the IFP programme for many years, but it appears that they had become somewhat lax in their spray programmes against these pests. The key to changing this situation was a recommendation that growers should apply two buprofezin sprays per block, including a later application just before flowering. This change to the spray programme coincided with a dramatic reduction in infestations of mealybugs. This study was not able to determine if one spray in early spring would have had a similar effect.

\section{ACKNOWLEDGEMENTS}

We thank Dawn Hope and Jan Cox of Fruition who assessed many bins of apples, Duncan Hedderley (Plant \& Food Research) for assisting with the data analysis and the growers of the Apollo supply group in Hawke's Bay who participated in the research. This project was funded by Pipfruit New Zealand.

\section{REFERENCES}

Charles JG 1993. A survey of mealybugs and their natural enemies in horticultural crops in North Island, New Zealand, with implications for biological control. Biocontrol Science and Technology 3: 405-418.

Charles JG, Walker JTS, White V 1993. Resistance to chlorpyrifos in the mealybugs Pseudococcus affinis and P. longispinus in Hawkes Bay and Waikato pipfruit orchards. Proceedings of the 46th New Zealand Plant Protection Conference: 120-125.

Walker JTS, Hodson AJ, Wearing CH, Bradley SJ, Shaw PW, Tomkins AR, Burnip GM, Stiefel HE, Batchelor TA 1997. Integrated fruit production for New Zealand pipfruit: evaluation of pest management in a pilot programme. Proceedings of the 50th New Zealand Plant Protection Conference: 258263. 